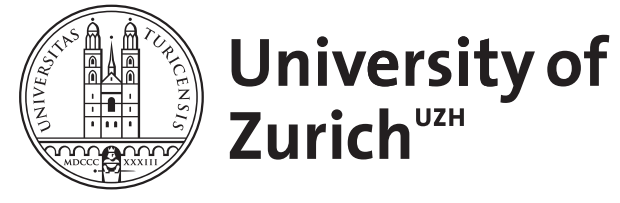

\title{
Laser-assisted microdissection applied to floral tissues
}

\author{
Wuest, Samuel E ; Grossniklaus, Ueli
}

\begin{abstract}
Cellular context can be crucial when studying developmental processes as well as responses to environmental variation. Several different tools have been developed in recent years to isolate specific tissues or cell types. Laser-assisted microdissection (LAM) allows for the isolation of such specific tissue or single cell-types purely based on morphology and cytology. This has the advantage that (1) cell types that are rare can be isolated from heterogeneous tissue, (2) no marker line with cell type-specific expression needs to be established, and (3) the method can be applied to non-model species and species that are difficult to genetically transform. The rapid development of next-generation sequencing (NGS) approaches has greatly advanced the possibilities to perform molecular analyses in diverse organisms. However, there is a mismatch between currently available cell isolation tools and their applicability to nonmodel organisms. Therefore, LAM will become increasingly popular in the study of diverse agriculturally or ecologically relevant plant species. Here, we describe a protocol that has been successfully used for LAM to isolate either whole floral organs or even single cell types in plants, e.g., Arabidopsis thaliana, Boechera spp., or tomato.
\end{abstract}

DOI: https://doi.org/10.1007/978-1-4614-9408-9_19

Posted at the Zurich Open Repository and Archive, University of Zurich

ZORA URL: https://doi.org/10.5167/uzh-90488

Book Section

Accepted Version

Originally published at:

Wuest, Samuel E; Grossniklaus, Ueli (2014). Laser-assisted microdissection applied to floral tissues. In: Riechmann, José Luis; Wellmer, Frank. Methods in Molecular Biology: Flower Development. New York, Heidelberg, Dordrecht, London: Springer, 329-344.

DOI: https://doi.org/10.1007/978-1-4614-9408-9_19 


\section{Laser-assisted microdissection applied to floral tissues}

Samuel E. Wuest ${ }^{1,2}$ and Ueli Grossniklaus ${ }^{2}$

Affiliations:

1) Institute of Evolutionary Biology and Environmental Studies \& Zürich-Basel Plant Science Center, University of Zurich, Winterthurerstrasse 190, CH-8057 Zürich, Switzerland

2) Institute of Plant Biology \& Zürich-Basel Plant Science Center, University of Zürich, Zollikerstrasse 107, CH-8008 Zürich, Switzerland

Corresponding author: Ueli Grossniklaus; grossnik@botinst.uzh.ch

Running head: Laser-assisted microdissection of floral tissues 


\section{Summary}

Cellular context can be crucial when studying developmental processes as well as responses to environmental variation. Several different tools have been developed in recent years to isolate specific tissues or cell types. Laser-assisted microdissection allows for the isolation of such specific tissue or single cell-types purely based on morphology and cytology. This has the advantage that (i) cell types that are rare can be isolated from heterogeneous tissue, (ii) no marker line with cell type-specific expression needs to be established, and (iii) the method can be applied to non-model species and species that are difficult to genetically transform. The rapid development of nextgeneration sequencing (NGS) approaches has greatly advanced the possibilities to perform molecular analyses in diverse organisms. However, there is a mismatch between currently available cell isolation tools and their applicability to non-model organisms. Therefore laser-assisted microdissection will become increasingly popular in the study of diverse agriculturally or ecologically relevant plant species. Here, we describe a protocol that has been successfully used for laser-assisted microdissection to isolate either whole floral organs or even single cell types in plants, e.g. Arabidopsis thaliana, Boechera spp. or tomato.

Keywords: Laser-assisted microdissection, single cell isolation, microgenomics

\section{Introduction}


Cellular context can provide important insights into the molecular bases underlying developmental processes, as cell-specific processes are often masked in experiments that are performed at the organ or whole-plant level (reviewed in [1]). Over the last years, several methods have been developed that allow the isolation of specific cell types or tissues (e.g. see examples in [2]). However, several popular cell isolation methods, such as fluorescence-activated cell sorting [3] (see Chapter 17) or the isolation of nuclei from specific cell types by affinity purification [4,5], rely on the use of transgenic lines and the availability of cell type-specific expression markers. At the same time, with the advances of NGS methods it has become possible to perform new types of experiments using non-model organisms. For example, RNA-Seq (see Chapter 23) offers the opportunity to study global gene expression even in organisms that lack reference sequences [6]. However, these non-model organisms might not be suitable for genetic transformation, meaning that there is a mis-match between the advances in NGS and the ability to understand cell type-specific expression. In these cases, laser-assisted microdissection (LAM) [7] can be considered the method of choice for the isolation specific cell or tissue types. No cell-specific expression marker line needs to be established, and the method can be applied to any species, including those that are difficult to genetically transform.

\subsection{What is LAM?}

LAM allows for the isolation of tissue subtypes [8-15] or even single cell types $[16,17,6]$, based purely on morphology or cytology (see Figure 1). LAM has been a very popular tool in biomedical research for over fifteen years, and also the plant research community has increasingly adopted it in recent years (e.g. in $[12,18,16,19,20,9])$. In preparation for LAM the target tissue is chemically fixed, embedded into a resin or wax, and sectioned 
using a microtome. A laser-based microdissection approach then allows the isolation of tissues or single cell types (or even subcellular domains [13]) from the sectioned specimens.

\subsection{Existing microdissection devices}

Several microdissection devices have been developed over the last fifteen years. These can be roughly classified into laser-capture (use of infrared-lasers to melt the tissue area of interest to a thermoplastic polymer) and laser-cutting (use of UV-laser to photovolatize tissue and slide membrane); please refer to e.g. [21] and [22] for an indepth review of these approaches.

Our protocol describes the use of a Molecular Machines and Industries (MMI) lasercutting device, such as the MMI CellCut Plus, which is equipped with a UV-laser that is well suited for the isolation of very small tissues or single cell types (e.g. egg cells with a diameter of 8-10 $\mu \mathrm{m}$ [16]). In principle, the MMI device is even suited for the isolation of certain subcellular domains (Marc Schmid and Ueli Grossniklaus, unpublished). Using this device, we have shown that it is also possible to dissect whole-mount tissues, whereby fine structures are attached directly to the membrane slide (Anupama Goyal, Samuel Wuest and Ueli Grossniklaus, unpublished). Alternative devices for LAM include the Arcturus Pix Cell II, the PALM XZ or the Leica AS LMD (see e.g. [21] and [23] for indepth descriptions of the different devices). However, the same fixation, embedding, and sectioning steps as described here can be applied for all of these microdissection devices.

\subsection{A simple protocol for LAM resembling in situ hybridization procedures}

If LAM and/or in situ hybridization are to be performed on a regular basis, it is advisable 
to automate certain steps of the protocols. For example, we generally perform the tissue embedding using the automated embedding system ASP200 from Leica. Such an embedding device allows for a streamlined, fast and reproducible workflow, cuts down on the time invested into sample collection, and provides results of higher reproducibility. However, such automated systems require a significant investment. Here, we describe a manual embedding method that takes several days, yet with little work required on most days. It is similar to a protocol typically used for in situ hybridization preparations (see Chapter 14), for which the expertise might already be available within a research group. Different methods, such as microwave-based embedding procedures that allow for shorter embedding periods, have been described elsewhere $[23,24]$.

\subsection{Common downstream applications}

Since the amount of isolated cellular material is often limited during LAM, downstream applications mostly focus on biomolecules that can be amplified before measurements. LAM is thus most commonly used in combination with gene expression profiling. Therefore, we consider here a protocol that aims at the extraction of RNA from the target cells for further downstream analyses. We advise on the use of precautions to preserve the integrity of the RNA in samples isolated by LAM, including carefully testing the RNA quality of the fixed, embedded, and laser dissected samples, respectively. In addition to gene expression studies, LAM has also been used for genotyping tissue, for instance young embryos and endosperm in developing seeds [25]. Recent efforts have focused on generating protocols to study DNA methylation status in single cell types $[26,27]$. These protocols are still being optimized and are not covered here. 


\subsection{Making the first step}

We have experienced that even though many researchers are interested in applying the technique to answer a specific scientific question, they hesitate to do so because LAM is considered a complicated, time-consuming and expensive technique. However, many steps of the LAM protocol are similar to those used in in situ hybridization methods, meaning that pre-existing expertise and tools for this technique can be applied (e.g. tissue fixation and embedding, sectioning using a microtome, etc.). Furthermore, for local access options to a microdissection device, it is advisable to check the availability at other departments of the university campus, such as the biomedical department.

\subsection{Experimental design}

Experimental design forms the base of any experiment in research, and in the case of LAM, it is advisable to consider the following points:

1. Types of design and general design issues: In any experiment that involves LAM, the need for the collection of specific cell types or tissues represents an additional sampling effort, which might include several rounds of optimization steps before the actual experiment can start. We have experienced in the past that once the workflow has been established, the sampling effort is often underestimated, and that sampling can extend over a substantial time period. For example, it is not rare that a molecular analysis fails due to limited input of biomolecules, especially when working at the technical limits. Also, samples from different treatments have to be processed in parallel and isolated at the same time, for otherwise confounding variables can be introduced.

We therefore advise to (at least initially) perform experiments with relatively simple experimental designs (e.g. two categorical explanatory variables such as 
treatment1/treatment2, or cell type1/cell type2) and focus on appropriate replication and controls. It should also be kept in mind that confounding could also happen through comparison of cell types that are not equally amenable to isolation by LAM (e.g. in comparisons of large structures against small structures that can yield different RNA qualities after LAM).

Furthermore, we argue that pooling of isolated tissue, which is often necessary to obtain sufficient amounts of biomolecules, does not substitute for proper experimental replication and randomization.

2. Costs: Even though the costs of consumables used during LAM are not excessively high, the downstream applications often involve optimized, commercially available kits (e.g. for RNA isolation and amplification, real-time RT-PCR, etc.). This makes intermediate quality control steps crucial and can quickly increase the overall costs. Again, this factor will promote the use of simple experimental design.

3. Automatisation: As described above, it can be beneficial to automate certain steps of the LAM protocol. For example, the use of automated embedding devices allows for more complex designs by improving reproducibility and speed of the experiments. In our laboratory, the embedding of material after fixation requires only an overnight step using the Leica ASP200 and reduces handling steps dramatically.

In summary, LAM has the potential to provide a detailed view of the abundance of biomolecules in specific plant tissues. It can provide important context to study developmental processes, but also cell type-specific responses to environmental signals. 


\section{Materials}

\subsection{Fixation:}

1) Absolute ethanol, analytical grade (see Note 1)

2) Glacial acetic acid, analytical grade (see Note 2)

3) Farmer's fixative: 3:1 (v/v) ethanol:acetic acid. Prepare fresh before fixation.

\subsection{Dehydration and embedding}

1) RNAseZAP® (Ambion) or other cleaning agent for removing RNases (important for RNA-based downstream applications)

2) Xylene for analysis

3) Paraplast Embedding Media (e.g. Sigma-Aldrich)

4) Glass vials (e.g. $20 \mathrm{~mL}$ ) with screw tops

5) Plastic weighing dishes

6) Oven (e.g. hybridization oven)

\subsection{Microtome sectioning}

1) Heating Table

2) Light table (or any light source below a semitransparent surface)

3) Embedding cassettes (or any block that can be used to mount tissue for microtome sectioning)

4) Razorblades

5) Microtome (e.g. RM2145 microtome, Leica)

6) RNase-free membrane slides ("MMI Molecular Machines \& Industries AG, 
Glattbrugg, Switzerland")

\subsection{Laser-assisted microdissection}

1) Microdissection device (e.g. mmi CellCut Plus device, MMI Molecular

Machines \& Industries AG, Glattbrugg, Switzerland)

2) MMI collection tubes (without diffuser)

3) Microscope glass slides, pre-baked for $6 \mathrm{~h}$ at $180^{\circ} \mathrm{C}$

4) For RNA-based work: PicoPure RNA extraction kit (Arcturus®)

\section{Methods}

\subsection{Fixation}

1. Prepare $40 \mathrm{~mL}$ of Farmer's fixative. Chill the fixative in a $-20^{\circ} \mathrm{C}$ freezer for at least 20 min (see Note 4).

2. Put $20 \mathrm{~mL}$ glass vials on ice and fill them with $5-10 \mathrm{~mL}$ of ice cold Farmer's fixative per vial (see Note 5).

3. Collect target tissue using fine forceps (see Note 6) and submerge them into the fixative in the glass vials.

4. Apply a soft vacuum for $10 \mathrm{~min}$, then release the vacuum slowly. Repeat the step once.

5. Change Farmer's fixative solution and keep tissue overnight on a shaker (shaking gently) at $4^{\circ} \mathrm{C}$.

Optional: after the fixation and overnight incubation, the tissue can be washed twice with 70\% ethanol prepared with DEPC-treated water, placed into ice-cold 
$70 \%$ ethanol and stored for a several days at $4^{\circ} \mathrm{C}$ if necessary.

\subsection{Dehydration and embedding}

\section{Day 1:}

1. Prepare aliquots of each $70 \%, 80 \%, 90 \%(\mathrm{v} / \mathrm{v})$ ethanol in DEPC-treated or RNase-free water, as well as pure ethanol and keep solutions at $4^{\circ} \mathrm{C}$. Keep samples on ice (or in the cold room) and on a shaker (shaking gently) for incubations.

2. Incubate tissue in $70 \%$ ethanol for $1 \mathrm{~h}$

3. Incubate tissue in $80 \%$ ethanol for $1 \mathrm{~h}$

4. Incubate tissue in $90 \%$ ethanol for $1 \mathrm{~h}$

5. Incubate tissue in $100 \%$ ethanol overnight

Optional: use $0.1 \%(\mathrm{w} / \mathrm{v})$ Eosin $\mathrm{Y}$ in ethanol to stain tissues during the overnight step (advisable for small or delicate tissues).

\section{Day 2:}

1. Prepare aliquots of each $25 \%, 50 \%$ and $75 \%(\mathrm{v} / \mathrm{v})$ xylene in ethanol. All steps can be performed at room temperature. Perform all steps involving xylene in a fume hood.

2. Incubate tissue in $100 \%$ ethanol for $1 \mathrm{~h}$

3. Incubate tissue in $100 \%$ ethanol for $1 \mathrm{~h}$

4. Incubate tissue in $25 \%$ xylene in ethanol for $1 \mathrm{~h}$

5. Incubate tissue in $50 \%$ xylene in ethanol for $1 \mathrm{~h}$ 
6. Incubate tissue in $75 \%$ xylene in ethanol for $1 \mathrm{~h}$

7. Incubate tissue in $100 \%$ xylene for $1 \mathrm{~h}$

8. Incubate tissue in $100 \%$ xylene for $1 \mathrm{~h}$

9. Incubate in $100 \%$ xylene with 1 Paraplast chip per $1 \mathrm{~mL}$ of xylene overnight.

\section{Day 3:}

1. Fill a $50 \mathrm{~mL}$ Falcon tube with Paraplast chips, heat to $54^{\circ} \mathrm{C}$, and let it melt (needed in step 4, below).

2. Add every half hour one Paraplast chip per $1 \mathrm{~mL}$ of xylene used, until the Paraplast chips no longer dissolve. During this step, keep samples at room temperature.

3. Put samples to $42^{\circ} \mathrm{C}$ and slowly add Paraplast chips (one by one per $1 \mathrm{~mL}$ of xylene every half hour).

4. After 2-3 h, carefully decant half of the xylene-Paraplast-mixture in the vials and replace with liquid Paraplast from point 1 at $54^{\circ} \mathrm{C}$.

5. Transfer samples into $54^{\circ} \mathrm{C}$.

6. After 2-3 h replace remaining xylene-Paraplast-mixture in the vials with liquid paraplast at $54^{\circ} \mathrm{C}$.

7. Refill the Falcon tube containing melted Paraplast with Paraplast chips.

\section{Day 4-6:}

1. Change paraplast twice a day and keep samples at $54^{\circ} \mathrm{C}$.

\section{Day 7:}

1. Prewarm weighing dishes (plastic "boats") at $54^{\circ} \mathrm{C}$ on a heating table. 
2. Pour Paraplast containing the target tissue into the dishes, then place the tissue samples in a desired position using pre-warmed tweezers or needles. Keep enough space between different samples.

3. Slowly cool down the dishes, and store blocks at $4^{\circ} \mathrm{C}$ until use (see Note 7).

\subsection{Sectioning and slide preparation}

1. Clean working area with RNaseZAP.

2. Dissect paraffin blocks containing the target tissue into small blocks (e.g. each containing one inflorescence) using a sharp razor blade and mount them onto embedding cassettes using a hot spatula (see Note 8).

3. Chill the mounted blocks at $4^{\circ} \mathrm{C}$ for $10-20 \min ($ see Note 9 ).

4. Cut the paraffin blocks on a microtome to 6-15 $\mu \mathrm{m}$ thickness (see Note 10) after cleaning the microtome surfaces with RNaseZAP.

5. Transfer ribbons onto a black surface (e.g. a black sheet of paper in a plastic box) and examine them under a binocular microscope. If possible, remove parts of the ribbon that do not contain any tissue of interest.

6. Mount the ribbons onto membrane-coated microdissection slides (see Note 11). Mounting can be performed by "fishing" the ribbons floating in a small water bath (RNase-free water) in a pre-backed glass container (see Note 12). Alternatively, drop a few milliliters of water onto the slide surface, place the ribbons onto the water and then pour the water off over one edge (see Note 13).

7. Dry the slides overnight on a heating table at $42^{\circ} \mathrm{C}$.

\subsection{Laser-assisted microdissection (LAM)}


1. Deparaffinize slides in $100 \%$ xylene at room temperature for $2 \times 10$ min before processing. Perform this step under a fume hood.

2. Dry the slides under the fume hood for at least $20 \mathrm{~min}$ before proceeding to LAM.

3. Turn on the microscope, laser and computer that are part of the LAM system.

4. Sandwich the tissue on the membrane-slide onto a normal glass slide (pre-baked at $180^{\circ} \mathrm{C}$ for $>6 \mathrm{~h}$, see Materials).

5. Open the MMI software tool that controls laser, stage motor, and cap lift. Set the laser speed, laser focus and laser power, and calibrate the stage movement and laser position (see Note 14).

6. Use the software to define the slide edges and scan the slide at $4 \mathrm{x}$ magnification to obtain a roadmap of the slide.

7. Insert the isolation cap into the cap holder, open the tube, and attach the cap holder to the cap lift.

8. Jump from tissue section to tissue section (use the roadmap to locate tissue sections) and identify the cells of interest (see Note 15).

9. Once an area of interest has been identified, lower the cap lift onto the membrane slide using the cap-lift tool.

10. Use a selection tool (e.g. "hand pen"-tool) to outline the cells of interest on the computer screen, then press "cut".

11. Raise the cap lift to see whether the section of interest is stuck to the surface of the isolation cap lid (see Note 16).

12. Several sections can now be bulked on the same isolation cap. When finished, remove the isolation cap from the cap holder and close the tube.

13. Proceed to the extraction of biomolecules directly, or freeze the collection tubes 
until further use (e.g. at $-80^{\circ} \mathrm{C}$ for RNA-related work).

\subsection{Extraction of RNA for downstream analyses and quality controls}

1. RNA-extraction methods and pooling: Several methods for extracting RNA from laser-dissected material have been compared by Kerk and colleagues [12]. They found that the Arcturus $®$ PicoPure RNA extraction kit (including a DNAsetreatment) results in highest yields, but other methods would also be suitable. We have used the PicoPure kit repeatedly and found it well suited to extract RNA from dissected material. The extraction method involves very simple procedures, and the kit manual provides easy-to-follow instructions.

Pooling: It is often advisable to pool several tissue fragments together to achieve higher yields (see Figure 2A). This can be done by (i) pooling different fragments on the same isolation cap, or (ii) pooling several caps for RNA extraction. The latter can be achieved by incubating several caps independently with RNA extraction buffer, pool the resulting extracts in a single tube, adding an equivalent volume of the $70 \%$ ethanol provided in the kit (e.g. $20 \mu \mathrm{L}$ to $2 \times 10 \mu \mathrm{L}$ extracts), and applying the pooled extracts to a single column.

2. Expected yields: It is difficult to estimate the yields obtained from laser-dissected cells or tissue, since concentrations after extraction often lie outside the dynamic range of current assays for estimating RNA quantities (see Note $\mathbf{1 7}$ for a short review of expected yields). Yields can be estimated, for example, by using the Qubit® Fluorometer (Life Technologies). 
3. RNA-quality: Due to limited yields during LAM, the quality of the collected samples often cannot be directly assessed. Therefore, we recommend isolating large tissue fragments from non-target tissues from the processed slides to obtain an alternative quality estimate. RNA integrity can be best checked by electrophoresis, e.g. by the use of a microcapillary-based system such as the Bioanalyzer Pico RNA kit (Agilent; see Note 18)

4. Downstream RNA-based applications: RNA extracted from LAM samples can be used directly in combination with semiquantiative or real-time RT-PCR, which is possible when larger tissue fragments such as floral buds or inflorescence meristems are isolated (e.g. [28,19] and see Figure 2C and D). For this, however, it is crucial to test the dynamic range of the PCR assays used. This can be done by performing serial dilution curve experiments that include total RNA concentrations of less than $1 \mathrm{ng} / \mu \mathrm{L}$. When working with few cells only, an amplification of the mRNA prior to the real-time RT-PCR experiment is usually necessary. For this, several protocols are available [29-31], in addition to a range of commercially available amplification kits (e.g. based on in vitro transcription amplification or PCR-based methods, see [21] for a review). Examples of commercially available kits are the NuGEN Ovation ${ }^{\circledR}$ Pico WTA systems (www.nugeninc.com and [32]), or mRNA amplification kits from Clontech (www.clontech.com).

The past few years have seen the rise of NGS-based transcriptional profiling, which is likely replacing hybridization-based methods such as microarray profiling in the future $[33,6]$. Collecting rather large tissue fragments during LAM 
will enable direct use of the isolated mRNA for NGS approaches (e.g. sequencing with the Illumina HiSeq requires a little as 50-100 ng of total RNA for mRNA-Seq). Recently, the application of mRNA-Seq has also been adopted for small RNA inputs [34-37]. These methods either depend on PCR-based amplifications or invitro transcription RNA from cDNA templates; at the same time, new protocols are rapidly being developed and comparisons between methods are still rare (but see also [38] for a recent review of the methods). In addition, several kits have been developed very recently for applications such as mRNA-Seq. For example, an Illumina protocol recommends the use of the SMARTer ultra low input RNA kit (www.clontech.com, see also [35] for a use of the SMART technology), for which starting material ranging from 0.1 to $10 \mathrm{ng}$ of total RNA can be amplified. Another recent release is the Ovation ${ }^{\circledR}$ RNA-Seq System V2 from NuGEN (www.nugeninc.com and [37]), where 0.5-100 ng of total RNA can be amplified and channeled into different existing sequencing library preparation protocols. Developments in the field are rapid, and optimized protocols and kits will soon become available for different NGS platforms, as well as different applications tailored for the different types of RNA molecules to be sequenced.

\section{Notes}

1: CAUTION: Ethanol liquid and vapour are highly flammable: keep away from heat sources and open flames and use appropriate ventilation

2: CAUTION: Acetic acid causes severe skin burns and eye damage and liquid and vapour are flammable - wear protective gloves, protective clothing, and eye protection; 
best handle in a fume hood.

3: To prepare DEPC-treated water, add DEPC at a concentration of $0.1 \%(\mathrm{v} / \mathrm{v})$ to ultrapure water (e.g. $1 \mathrm{~mL}$ to $1 \mathrm{~L}$ ). Stir and incubate overnight and then autoclave. Autoclaving will decompose DEPC and render it non-toxic. CAUTION: DEPC is toxic, and handling should be performed under a hood while wearing appropriate protection.

4: The choice of fixative generally determines (i) the histological preservation of sectioned tissues, and (ii) the preservation and extractability of biomolecules from the dissected tissue $[39,12]$. Farmer's fixative with subsequent embedding into paraplast has been found to be a good choice for work with plant tissues $[12,40,23]$. Acetone- or phosphate buffer-based fixation methods have also been applied in the plant sciences $[23,19]$. While animal and biomedical researchers tend to snap-freeze and cryosection tissues for an optimal preservation of biomolecules [41], this procedure tends to yield poor histological preservation of plant tissues (especially in mature tissues containing large vacuoles) [21]. On the other hand, there is ample literature available that advises against the use of cross-linking fixatives such as paraformaldehyde (which generally yields better histological preservation) - these fixatives generally result in poor quality and low yields of biomolecules for downstream applications [39,12].

5: The volume of fixative is dependent on the tissue type and size collected. 5-10 mL is well suited for the fixation of 10-20 Arabidopsis inflorescences. For larger tissues, the volume should be increased so that a large excess of fixative as compared to tissue is achieved. 
6: When collecting inflorescences, it is advisable to remove as many large, undesired structures (such as maturing siliques) as possible. For collecting cells from young flowers or inflorescence meristems, remove all larger flowers on the inflorescence.

7: We have stored tissue embedded in paraffin blocks for several weeks in the fridge without considerable loss of RNA quality

8: Mounting can be done be heating a spatula containing a small piece of paraplast on a flame and pouring the liquid paraplast onto the cassette. Immediately press the block onto the solidifying paraplast. Re-heat the spatula and press it weakly against the lower side of the block to seal the remaining gaps between block and cassette.

9: Try to section samples on the microtome when the blocks are still cold. This will generally improve the tissue morphology.

10: The choice of the thickness of the microtome sections depends on the tissue of interest. It is advisable to cut thicker sections if larger tissue is harvested, since this will often lead to better integrity of the RNA. When dissecting single cells, sections should be thinner $($ e.g. 6-8 $\mu \mathrm{m})$ to reduce contamination with non-target tissue and to render cytological features more prominent.

11: Mounting of the ribbons has to occur on the membrane-coated side of the MMI microdissection slide, so that the tissue can later be sandwiched between a pre-backed glass slide and the membrane. 
12: All glassware used for RNA-based experiments should be baked before use at $180^{\circ} \mathrm{C}$ for at least $6 \mathrm{~h}$.

13: It has been suggested that RNA degradation can sometimes occur even when using RNAse-free water for mounting the ribbons onto membrane-coated LAM slides [42]. Furthermore, when LAM is applied to very rare cell types for which only few cells can be harvested in a realistic time frame, high RNA quality of the target tissue is of central importance. A previously published method includes a tape-based paraffin section mounting system, which improved RNA quality considerably [42]. In our lab, the use of methanol instead of RNAse-free water for mounting the paraffin sections onto the slides yielded a more consistent quality of RNA (see also [17] and Anja Schmidt, personal communication; CAUTION: Methanol is toxic. Perform the mounting under a fume hood and wear lab coat, protective gloves and safety glasses.)

14: Laser and stage calibration have to be performed for each objective separately as described in the technical manual. Generally, these calibrations need only be performed once per computer user. For each of the objectives used during the actual laser dissection, the laser speed, focus and energy levels have to be adjusted separately. The laser focus is generally the most important parameter for optimal results. We recommend against the use of high power-settings, since scattered energy might result in damage and lower yields of biomolecules.

15: LAM is normally applied to fixed and dehydrated tissue sections. In these, the histological preservation might be different from normally mounted and rehydrated tissue sections. It is therefore advisable to assess in advance whether and how the cells 
of interest can be identified in dehydrated sections. Rehydration of the sections can be considered for some laser devices [40].

16: Sometimes, the dissected area of interest does not adhere to the isolation cap, or gets folded out of the focal plane when the cap lift is raised. This can have several reasons, for example: (i) the laser did not completely cut all the tissue. Try to optimize the laser settings, firstly by adjusting the laser focus, lowering the speed and, if necessary, increasing the power. Alternatively, set the cutting repeats to $2 x$. (ii) The section of interest is too close to the border of the slide, so that lowering the isolation cap onto the membrane does not work anymore. The cap might be sitting on the metal frame of the slide. Lowering the cap onto the slide membrane should result in a change of the focal plane position of the tissue.

17: Yields also strongly depend on the organism, the cell type isolated, the fixation method used, RNA preservation during the isolation process, the thickness of microtome sections, and the size of laser-dissected fragments. For example, differentiated cells such as from the Arabidopsis hypocotyl are generally larger but contain large vacuoles and yield smaller RNA quantities per area unit. On the other hand, meristematic tissues contain a large number of small, transcriptionally active cells with small vacuoles, and yield larger RNA quantities ([29] and personal observations). Thus, yield estimates for different organisms and cell types range widely between approximately 0.5-10 ng per 100 cells isolated [21]. Published reports of yields reflect this diversity. On one side, Kerk and colleagues obtained an average of approximately 12 ng and 17 ng per 100 isolated cells from maize bundle sheaths or radish hypocotyls, respectively. On the other hand side, Day and colleagues estimated RNA yields from Arabidopsis endosperm, seed 
coat, and embryo tissue, and obtained estimates of around 0.2-0.6 ng of RNA per isolated fragments (equivalent to sections of $\sim 20-60$ cells). They could isolate in the range of 2060 ng of total RNA by pooling 100 isolated fragments. Cai and Lashbrook estimated an average yield of 1.0-1.5 ng of total RNA from 100 Arabidopsis petal or stamen abscission zone cells [42]. In our work, we have typically obtained yields similar to the latter two reports (e.g. when isolating Arabidopsis inflorescence meristems, data not shown). On the other hand, we were not able to accurately determine the yields isolated from pooled single gametophyte cells before two rounds of linear RNA amplification, but a microarray-based characterization of cellular transcriptomes required between 300 and 800 single cell fragments [16].

18: RNA integrity can be estimated by the RNA size distributions and the presence and size of ribosomal RNA peaks in total RNA extracts (see Figure 2B). Embedded and laserdissected plant material will generally result in some reduction of the RNA quality, but ribosomal peaks should still be visible in total RNA extracts. Even though RNA degradation could generally happen at multiple steps during the LAM protocol, it has been suggested that mounting the microtome-dissected ribbons onto the membranecoated slides is a critical step during the process (see Note 13).

\section{Acknowledgements}

The authors would like to acknowledge Chloé Wuest and Anja Schmidt for reading of the manuscript, and Marc Schmid for providing Figure 2B. S.E.W. is supported by a Marie Curie Intra European Fellowship within the 7th European Community Framework Programme, and work on cell-specific profiling methods in U.G.'s laboratory is 
supported by the University of Zürich and the Swiss National Science Foundation.

\section{References:}

1. Rogers ED, Jackson T, Moussaieff A, Aharoni A, Benfey PN (2012) Cell type-specific transcriptional profiling: implications for metabolite profiling. Plant J 70 (1):5-17.

2. Taylor-Teeples M, Ron M, Brady SM (2011) Novel biological insights revealed from cell typespecific expression profiling. Curr Opin Plant Biol 14 (5):601-607.

3. Birnbaum K, Shasha DE, Wang JY, Jung JW, Lambert GM, Galbraith DW, Benfey PN (2003) A gene expression map of the Arabidopsis root. Science 302 (5652):1956-1960.

4. Henry GL, Davis FP, Picard S, Eddy SR (2012) Cell type-specific genomics of Drosophila neurons. Nucleic Acids Res 40 (19):9691-9704.

5. Deal RB, Henikoff S (2010) A simple method for gene expression and chromatin profiling of individual cell types within a tissue. Dev Cell 18 (6):1030-1040.

6. Schmid MW, Schmidt A, Klostermeier UC, Barann M, Rosenstiel P, Grossniklaus U (2012) A powerful method for transcriptional profiling of specific cell types in eukaryotes: laser-assisted microdissection and RNA sequencing. PLoS One 7 (1):e29685.

7. Emmert-Buck MR, Bonner RF, Smith PD, Chuaqui RF, Zhuang Z, Goldstein SR, Weiss RA, Liotta LA (1996) Laser capture microdissection. Science 274 (5289):998-1001

8. Brooks L, 3rd, Strable J, Zhang X, Ohtsu K, Zhou R, Sarkar A, Hargreaves S, Elshire RJ, Eudy D, Pawlowska T, Ware D, Janick-Buckner D, Buckner B, Timmermans MC, Schnable PS, Nettleton D, Scanlon MJ (2009) Microdissection of shoot meristem functional domains. PLoS Genet 5 (5):e1000476.

9. Ohtsu K, Smith MB, Emrich SJ, Borsuk LA, Zhou R, Chen T, Zhang X, Timmermans MC, Beck J, Buckner B, Janick-Buckner D, Nettleton D, Scanlon MJ, Schnable PS (2007) Global gene expression analysis of the shoot apical meristem of maize (Zea mays L.). Plant J 52 (3):391-404.

10. Spencer MW, Casson SA, Lindsey K (2007) Transcriptional profiling of the Arabidopsis embryo. Plant Physiol 143 (2):924-940.

11. Cai S, Lashbrook CC (2008) Stamen abscission zone transcriptome profiling reveals new candidates for abscission control: enhanced retention of floral organs in transgenic plants overexpressing Arabidopsis ZINC FINGER PROTEIN2. Plant Physiol 146 (3):1305-1321.

12. Kerk NM, Ceserani T, Tausta SL, Sussex IM, Nelson TM (2003) Laser capture microdissection of cells from plant tissues. Plant Physiol 132 (1):27-35.

13. Le BH, Cheng C, Bui AQ, Wagmaister JA, Henry KF, Pelletier J, Kwong L, Belmonte M, Kirkbride R, Horvath S, Drews GN, Fischer RL, Okamuro JK, Harada JJ, Goldberg RB (2010) Global analysis of gene activity during Arabidopsis seed development and identification of seed-specific transcription factors. Proc Natl Acad Sci U S A 107 (18):8063-8070.

14. Walia H, Josefsson C, Dilkes B, Kirkbride R, Harada J, Comai L (2009) Dosage-dependent deregulation of an AGAMOUS-LIKE gene cluster contributes to interspecific incompatibility. Curr Biol 19 (13):1128-1132.

15. Deeken R, Ache P, Kajahn I, Klinkenberg J, Bringmann G, Hedrich R (2008) Identification of Arabidopsis thaliana phloem RNAs provides a search criterion for phloem-based transcripts hidden in complex datasets of microarray experiments. Plant J 55 (5):746-759.

16. Wuest SE, Vijverberg K, Schmidt A, Weiss M, Gheyselinck J, Lohr M, Wellmer F, Rahnenfuhrer J, von Mering C, Grossniklaus U (2010) Arabidopsis female gametophyte gene expression map reveals similarities between plant and animal gametes. Curr Biol 20 (6):506-512.

17. Schmidt A, Wuest SE, Vijverberg K, Baroux C, Kleen D, Grossniklaus U (2011) Transcriptome analysis of the Arabidopsis megaspore mother cell uncovers the importance of RNA helicases for plant germline development. PLoS Biol 9 (9):e1001155.

18. Casson S, Spencer M, Walker K, Lindsey K (2005) Laser capture microdissection for the analysis of gene expression during embryogenesis of Arabidopsis. Plant J 42 (1):111-123.

19. Inada N, Wildermuth MC (2005) Novel tissue preparation method and cell-specific marker for laser microdissection of Arabidopsis mature leaf. Planta 221 (1):9-16. 
20. Chandran D, Inada N, Hather G, Kleindt CK, Wildermuth MC (2010) Laser microdissection of Arabidopsis cells at the powdery mildew infection site reveals site-specific processes and regulators. Proc Natl Acad Sci U S A 107 (1):460-465.

21. Day RC, Grossniklaus U, Macknight RC (2005) Be more specific! Laser-assisted microdissection of plant cells. Trends Plant Sci 10 (8):397-406.

22. Espina V, Wulfkuhle JD, Calvert VS, VanMeter A, Zhou W, Coukos G, Geho DH, Petricoin EF, 3rd, Liotta LA (2006) Laser-capture microdissection. Nat Protoc 1 (2):586-603.

23. Day RC (2010) Laser microdissection of paraffin-embedded plant tissues for transcript profiling. Methods Mol Biol 655:321-346.

24. Chandran D, Inada N, Wildermuth MC (2011) Laser microdissection of plant-fungus interaction sites and isolation of RNA for downstream expression profiling. Methods Mol Biol 712:241-262.

25. Nowack MK, Shirzadi R, Dissmeyer N, Dolf A, Endl E, Grini PE, Schnittger A (2007) Bypassing genomic imprinting allows seed development. Nature 447 (7142):312-315.

26. You W, Tyczewska A, Spencer M, Daxinger L, Schmid MW, Grossniklaus U, Simon SA, Meyers BC, Matzke AJ, Matzke M (2012) Atypical DNA methylation of genes encoding cysteine-rich peptides in Arabidopsis thaliana. BMC Plant Biol 12:51.

27. Wöhrmann HJ, Gagliardini V, Raissig MT, Wehrle W, Arand J, Schmidt A, Tierling S, Page DR, Schob H, Walter J, Grossniklaus U (2012) Identification of a DNA methylation-independent imprinting control region at the Arabidopsis MEDEA locus. Genes Dev 26 (16):1837-1850.

28. Liu X, Kim YJ, Muller R, Yumul RE, Liu C, Pan Y, Cao X, Goodrich J, Chen X (2011)

AGAMOUS terminates floral stem cell maintenance in Arabidopsis by directly repressing WUSCHEL through recruitment of Polycomb Group proteins. Plant Cell 23 (10):3654-3670.

29. Scanlon MJ, Ohtsu K, Timmermans MC, Schnable PS (2009) Laser microdissection-mediated isolation and in vitro transcriptional amplification of plant RNA. Curr Protoc Mol Biol Chapter 25:Unit 25A 23.

30. Van Gelder RN, von Zastrow ME, Yool A, Dement WC, Barchas JD, Eberwine JH (1990)

Amplified RNA synthesized from limited quantities of heterogeneous cDNA. Proc Natl Acad Sci U S A 87 (5):1663-1667

31. Wang E (2005) RNA amplification for successful gene profiling analysis. J Transl Med 3:28. 32. Vermeulen J, Derveaux S, Lefever S, De Smet E, De Preter K, Yigit N, De Paepe A, Pattyn F, Speleman F, Vandesompele J (2009) RNA pre-amplification enables large-scale RT-qPCR geneexpression studies on limiting sample amounts. BMC Res see Notes 2:235.

33. Wang Z, Gerstein M, Snyder M (2009) RNA-Seq: a revolutionary tool for transcriptomics. Nat Rev Genet 10 (1):57-63.

34. Tang F, Barbacioru C, Wang Y, Nordman E, Lee C, Xu N, Wang X, Bodeau J, Tuch BB, Siddiqui A, Lao K, Surani MA (2009) mRNA-Seq whole-transcriptome analysis of a single cell. Nat Methods 6 (5):377-382.

35. Ramskold D, Luo S, Wang YC, Li R, Deng Q, Faridani OR, Daniels GA, Khrebtukova I, Loring JF, Laurent LC, Schroth GP, Sandberg R (2012) Full-length mRNA-Seq from single-cell levels of RNA and individual circulating tumor cells. Nat Biotechnol 30 (8):777-782.

36. Hashimshony T, Wagner F, Sher N, Yanai I (2012) CEL-Seq: single-cell RNA-Seq by multiplexed linear amplification. Cell Rep 2 (3):666-673.

37. Tariq MA, Kim HJ, Jejelowo O, Pourmand N (2011) Whole-transcriptome RNAseq analysis from minute amount of total RNA. Nucleic Acids Res 39 (18):e120.

38. Hebenstreit D (2012) Methods, challenges and potentials of single cell RNA-seq. Biology 1

(3):658-667

39. Gillespie JW, Best CJ, Bichsel VE, Cole KA, Greenhut SF, Hewitt SM, Ahram M, Gathright YB, Merino MJ, Strausberg RL, Epstein JI, Hamilton SR, Gannot G, Baibakova GV, Calvert VS, Flaig MJ, Chuaqui RF, Herring JC, Pfeifer J, Petricoin EF, Linehan WM, Duray PH, Bova GS, Emmert-Buck

MR (2002) Evaluation of non-formalin tissue fixation for molecular profiling studies. Am J Pathol 160 (2):449-457.

40. Day RC, McNoe LA, Macknight RC (2007) Transcript analysis of laser microdissected plant cells. Physiol Plantarum 129 (2):267-282.

41. Goldsworthy SM, Stockton PS, Trempus CS, Foley JF, Maronpot RR (1999) Effects of fixation on RNA extraction and amplification from laser capture microdissected tissue. Mol Carcinog 25 (2):8691. 
42. Cai S, Lashbrook CC (2006) Laser capture microdissection of plant cells from tape-transferred paraffin sections promotes recovery of structurally intact RNA for global gene profiling. Plant J 48 (4):628-637.

\section{Figures}
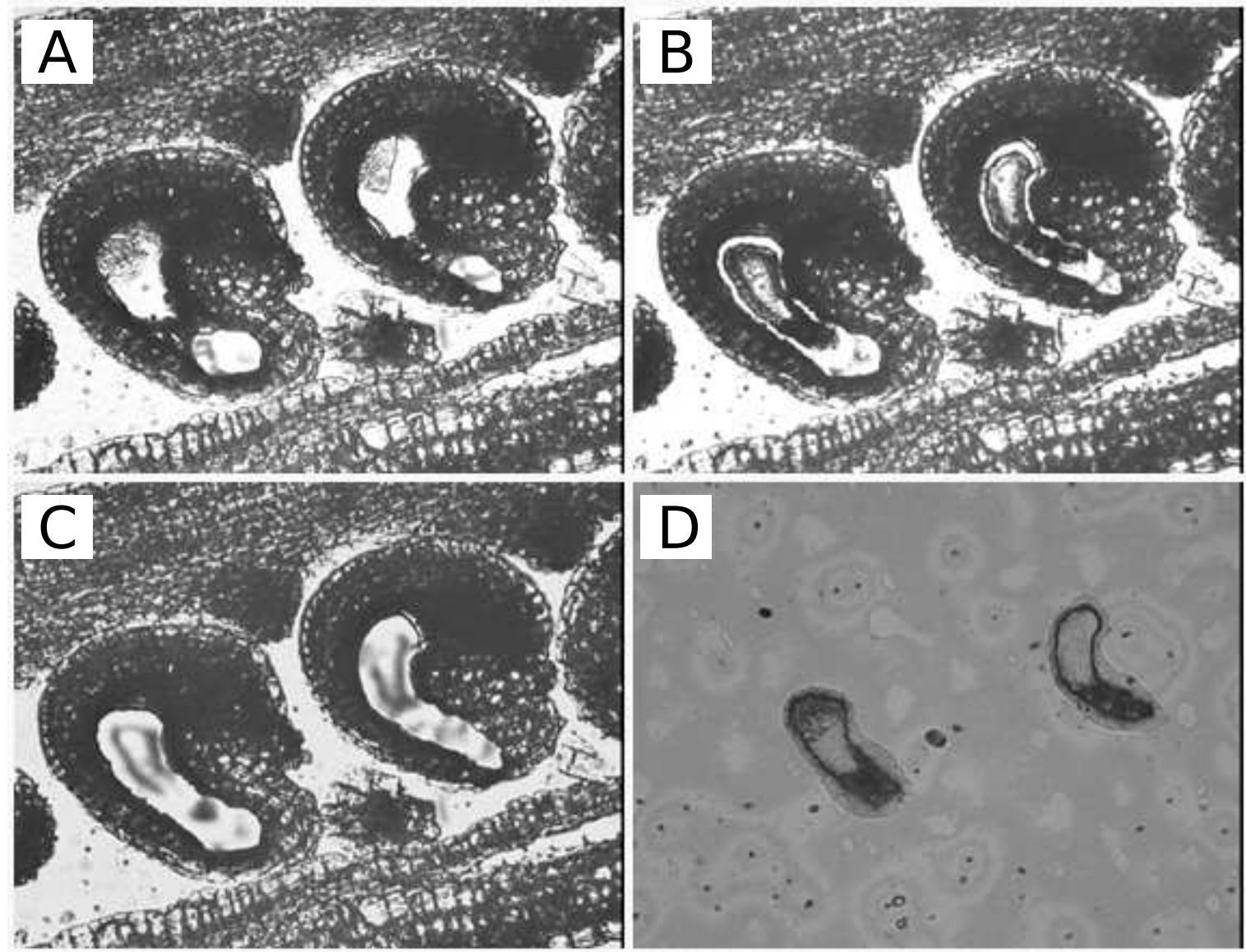

Figure 1: Laser-assisted microdissection of single cell-types from flowers. The

series shows LAM steps during the isolation of Arabidopsis thaliana central cells from 8 $\mu \mathrm{m}$ thick carpel sections. A. Two ovules containing two intact central cells (large, vacuolated cells in the center). B. Laser cutting performed with the MMI $\mu$ Cut system that uses a UV-laser beam to isolate tissue sections of interest. The laser beam has a diameter of approximately $1 \mu$ m. C. Removal of central cells from the carpel sections by the use of an adhesive cap from a collection tube. D. Isolated central cells attached to the 
adhesive cap, ready to be used for downstream applications (e.g. RNA extraction).
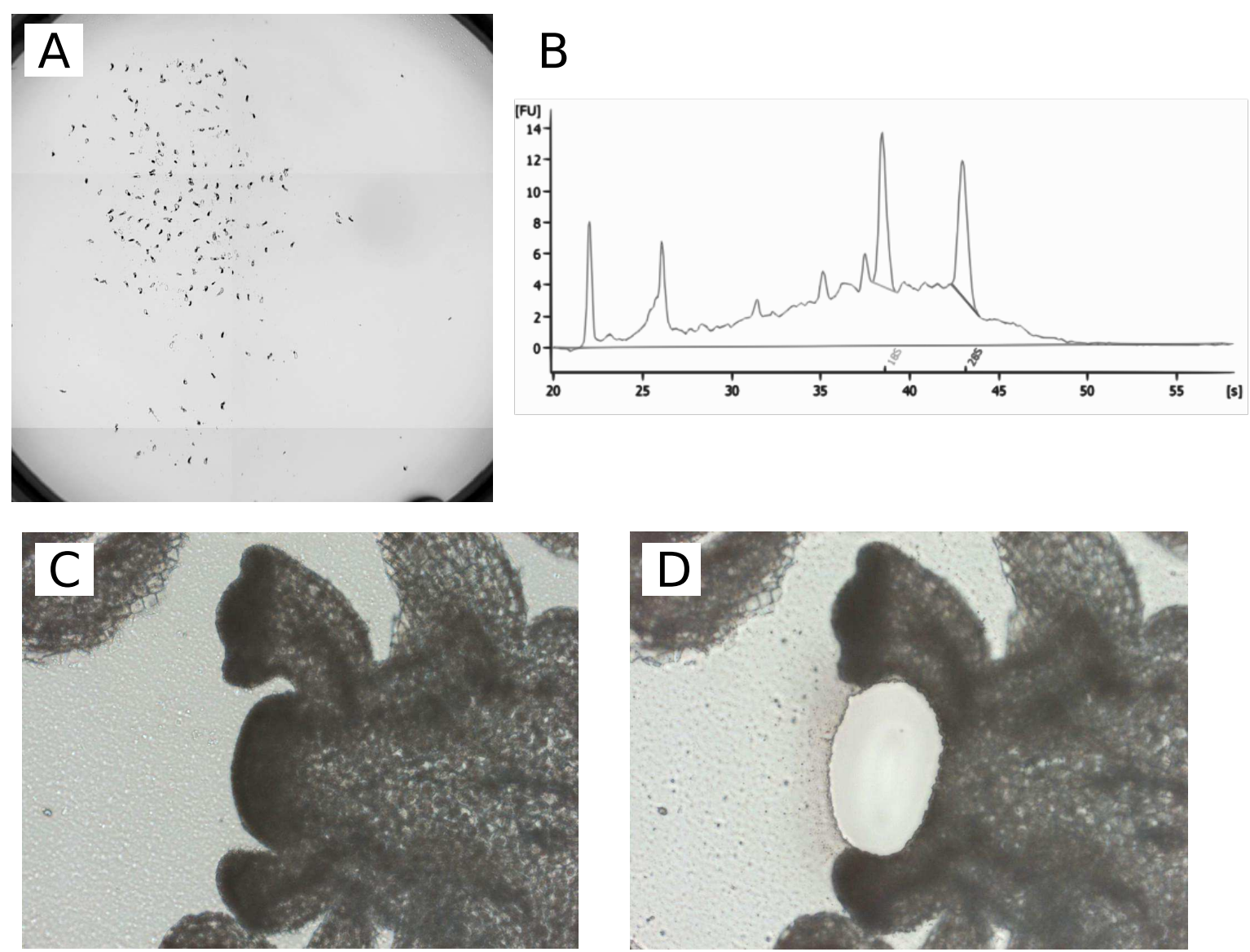

\section{Figure 2: Pooling tissue fragments and assessment of RNA quality for downstream}

application. A. Pooling of several central cells on a single cap (approximately 150 cell fragments), in addition to on-column pooling of RNA extracts from 3-4 caps was necessary to perform a cell-specific expression profiling experiment [16]. The exact quantity of the extracted RNA could, however, not be determined from the pooled sample. Please note that pooling does not substitute for replication. B. RNA electrophoresis profile (Bioanalyzer Pico Chip) of large floral structures isolated using LAM. In this example, the $28 \mathrm{~S}$ and $18 \mathrm{~S}$ rRNA peaks are well visible, indicative of high quality total RNA. If the RNA quality of samples cannot be assessed directly, neighboring non-target tissue can be isolated as a surrogate to estimate sample RNA quality. C and D. 
Larger structures, such as Arabidopsis inflorescence meristems do not require as much pooling, and less than 10 isolated fragments can be used directly in real-time RT-PCR experiments without the need of an additional RNA amplification step (Marko Sesartić and Samuel Wuest, unpublished). 
